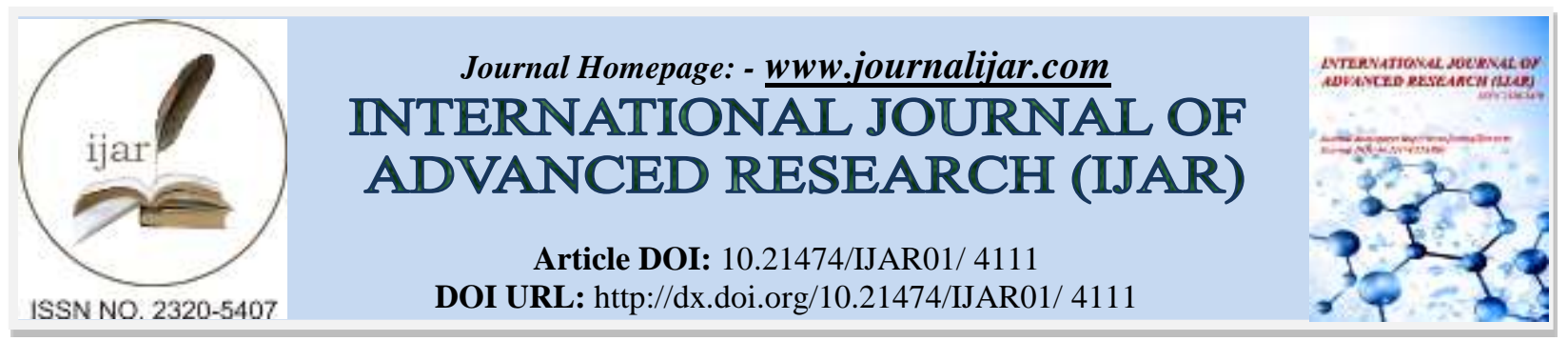

RESEARCH ARTICLE

\title{
PENETRATING KERATOPLASTY: INDICATION, OUTCOMES, AND COMPLICATION.
}

\author{
Dr. Pawan N. Jarwal ${ }^{1}$, Dr. Parth A. Leuva ${ }^{2}$ and Dr. S. S. Ganvit ${ }^{3}$ \\ 1. Third year resident doctor, department of ophthalmology, ssg hospital Vadodara. \\ 2. Senior resident doctor, department of ophthalmology,ssg hospital Vadodara. \\ 3. Associate professor department of ophthalmology, ssg hospital Vadodara.
}

\section{Manuscript Info}

Manuscript History

Received: 12 March 2017

Final Accepted: 14 April 2017

Published: May 2017

Key words:-

Penetrating keratoplasty, outcomes, indications, complications

\section{Abstract}

Purpose: This study is a modest and a humble attempt done with purpose of: analyzing the overall survival rate of corneal transplants, studying the various factors influencing the survival of the graft and studying the post-operative complications and correlating it with the several pre-operative, intra-operative and post-operative factors.

Methods: This prospective case note review identified 50 penetrating keratoplasties [25: Optical \& 25: Therapeutic] performed during a period from Sept.2015 to Aug.2016 at S. S. G. Hospital, Vadodara (India). All the patients were followed for a minimum period of 3 months. Throughout the statistical analysis, the patients were divided into two major groups: Optical and Therapeutic. Preoperative risk factor, surgical technique, postoperative complications were analyzed.

Results: Maximum incidence of KP [52\%] was seen in the age group $>60$ years [males and females inclusive]. Most frequent indication for OKP in the study cases was corneal leucomatous opacities [44\%], followed by Pseudophakic Bullous Keratopathy [32\%]. The age of majority of donor eyeballs was more than 60 years [68\%] or between 41-60 years [26\%] \{Total: $94 \%$ \}. The most common post-operative complications noticed were Vascularization [44\%] Immune rejection [34\%] glaucoma [26\% ]Uveitis [14\%] and infection [20\%]. The most probable causes of failure in Optical and Therapeutic cases were: Complications after surgery, Immune rejection reaction and Primary Endothelial failure.

Copy Right, IJAR, 2016,. All rights reserved.

\section{Introduction:-}

There are around 12 million blind persons in the country. Out of these $10 \%$ is due to corneal blindness including 2 , 70,000 childhood blindness cases ${ }^{1}$. Visual rehabilitation with corneal transplantation may be a possibility in many of these corneal blindness cases. So, also at times when severe corneal infection due to any reason jeopardize the structural integrity of eye ball and all other conservative measures fail, its penetrating keratoplasty, once again that comes to rescue ${ }^{4}$.

Outcomes, including failure and complication of procedure, are well known and appear dependent on several factors i.e. recipient etiology, preoperative comorbidity and health of donor tissue. Modern day success in 
transplantation is attributed to eye bank storage technique, ocular pharmacology, equipment and modern surgical technique ${ }^{2}$.

This fact has inspired this modest attempt to study the factors responsible for the failure of this sight restoring and integrity preserving surgery in our impoverished conditions.

\section{Materiales and Methods:-}

This prospective study will include 50 penetrating keratoplasties performed during a period from Sept.2015 to Aug.2016 at S. S. G. Hospital, Vadodara after taking all inclusion and exclusion criteria's in consideration .

\section{Inclusion criteria:-}

1)All the patients with visual acuity of minimum, light perception and projection of light rays in all quadrants.2)All cases with non healing corneal ulcers, recurrent corneal ulceration, perforated corneal ulcer and corneal ulcers not responding to any medical line of treatment were taken for therapeutic penetrating keratoplasty.3)All cases of leucomatous corneal opacities following any reason like trauma, ulcer, and chemical burns etc. but having at least good perception and projection of light and posterior segment anomaly ruled out on USG B-Scan.4)All case of corneal dystrophies and degeneration.5)All cases of keratoconus and ectasias.

\section{Exclusion criteria:-}

1) Patients not having light perception and projection of light rays.2) Patients with multiple graft failure.3) Patients with known case of glaucoma.4) Patients with uncontrolled D.M. \& H.T.5) Patients age less than 12 year.6) Pregnant females.

After taking written and informed consent about enrollment in the study and maintaining adequate privacy and confidentiality, all patients were undergoes all the standard pre-operative examination for keratoplasty surgery. Donor corneas were inspected and then trephined. Trephination of recipient corneas will be undertaken and donor corneas was sutured to recipient using 10/0 Ethicon sutures. Patients were discharged after 8-10 days and regular follow up of the patients were maintained as weekly for one month and around every 15 days for next two months. Local instillation of antibiotic and steroids where indicated will be continued with regular check-up of IOP during follow ups.During follow ups post- operative vision, tension, with slit lamp examination for graft clarity, epithelial defect, vascularization, ectasia, suture position and wound leakage, anterior chamber depth, any iris graft synechia were examined.

\section{Results:-}

Demography:-

Out of the 50 cases studied, 34 cases were male patients [68\%] and 16 cases were female patients [32\%].Maximum incidence of cases were in the age group of $>60$ year both in males and females.

Table 1:- Demography

\begin{tabular}{|l|l|l|l|}
\hline DIAGNOSIS & $21-40$ & $41-60$ & $>60$ \\
\hline Pseudophakic bullous keratopathy & 00 & 02 & 06 \\
\hline Aphakic bullous keratopathy & 00 & 01 & 01 \\
\hline Leucomatous corneal opacity & 02 & 05 & 04 \\
\hline Adherent leucoma & 00 & 00 & 02 \\
\hline Graft haziness & 01 & 00 & 00 \\
\hline Impending perforation & 00 & 00 & 01 \\
\hline
\end{tabular}

\section{Indication:-}

Most frequent indication for OKP in the study cases was Corneal leucomatous opacities (11/25) [44\%], followed by Pseudophakic Bullous Keratopathy [08/25] [32\%].

Most frequent indication for TKP in our study was perforated corneal ulcer (15/25) [60\%] followed by melted/non healing corneal ulcer [16\%] while the rest cases were done for corneal abscess ,perforation with anterior staphyloma and failed TKP. 
Table 2:- Indication Of Okp.

\begin{tabular}{|l|l|l|l|}
\hline \multicolumn{1}{|c|}{ DIAGNOSIS } & $21-40$ & $41-60$ & $>60$ \\
\hline Melted/Non healing Corneal Ulcer & 02 & 01 & 01 \\
\hline Perforated Corneal Ulcer & 01 & 05 & 09 \\
\hline Perforation with Anterior Staphyloma & 00 & 02 & 00 \\
\hline Corneal Abscess & 01 & 01 & 01 \\
\hline Failed Corneal Graft & 00 & 00 & 01 \\
\hline
\end{tabular}

\section{Study Of The Donor Factors}

Table 3:- Study Of The Donor Factors

\begin{tabular}{|c|c|c|}
\hline & OPTICAL & THERAPEUTIC \\
\hline \multicolumn{3}{|c|}{ 1)AGE } \\
\hline$<40$ years & 02 & 01 \\
\hline $41-60$ & 10 & 03 \\
\hline$>60$ years & 13 & 21 \\
\hline \multicolumn{3}{|c|}{ 2)CORNEAL CLARITY } \\
\hline EXCELLENT & 02 & 00 \\
\hline VERY GOOD & 08 & 04 \\
\hline GOOD & 15 & 12 \\
\hline FAIR & 00 & 08 \\
\hline POOR & 00 & 01 \\
\hline \multicolumn{3}{|c|}{ 3)PHAKIC STATUS } \\
\hline PHAK1C & 18 & 16 \\
\hline PSEUDOPHAKIC & 07 & 09 \\
\hline APHAKIC & 00 & 00 \\
\hline \multicolumn{3}{|c|}{ 4)TIME INTERVAL BETWEEN DEATH \& ENUCLEATION } \\
\hline $0-4 \mathrm{HR}$ & 10 & 05 \\
\hline $5-10 \mathrm{HR}$ & 04 & 19 \\
\hline $11-15 \mathrm{HR}$ & 01 & 01 \\
\hline$>15 \mathrm{HR}$ & 00 & 00 \\
\hline \multicolumn{3}{|c|}{ 5)TIME INTERVAL BETWEEN DEATH \& SURGERY } \\
\hline $0-4 \mathrm{HR}$ & 07 & 03 \\
\hline $5-10 \mathrm{HR}$ & 16 & 17 \\
\hline $11-15 \mathrm{HR}$ & 02 & 04 \\
\hline$>15 \mathrm{HR}$ & 00 & 01 \\
\hline
\end{tabular}

[All the eyeballs were stored in moist chamber at 4 deg C]

The age of majority of donor eyeballs was more than 60 years [68\%] or between 41-60 years [26\%] \{Total: 94\%\} .There were only $06 \%$ eyeballs younger than 40 years. $82 \%$ of the donor eyeballs had excellent, very good and good condition. Most of the donor eyes used for OKP were of very good and good condition [92\%]. $68 \%$ of the eyeballs were phakic and most of the eyeballs used for optical purpose were phakic [72\%].66\% of the eyeballs were enucleated within 5-10hrs of death and most of them were utilized within 10 hours [86\%].

All of the donor eyeballs were stored in moist chamber at 4 deg C. 


\section{Study Of The Recepient Factors:-}

Table 4:- Study Of The Recepient Factors .

\begin{tabular}{|c|c|c|}
\hline Recipient Factors & Optical & Therapeutic ; \\
\hline Vision (FC+) & 16 & 00 \\
\hline High intraocular pressure & 00 & 00 \\
\hline Abnormal Sac & 00 & 08 \\
\hline Vascularization & 14 & 06 \\
\hline Pseudophakic/Aphakic & 13 & 05 \\
\hline Systemic Disease & 07 & 03 \\
\hline Nutrition(Fair to poor) & 03 & 03 \\
\hline
\end{tabular}

$64 \%$ of the optical cases had Preop Vision of FC+ while therapeutic cases had PL+ Vision in only $16 \%$.

$56 \%$ of the Optical cases had vascularization of the host bed and 32\% therapeutic cases had vascularized bed.

Aphakia/Pseudophakia [52\%] was another significant finding in Optical cases while same is $32 \%$ in therapeutic keratoplasty.

Study Of Surgical Factor:-

Table 5:- Study Of The Surgical Factors.

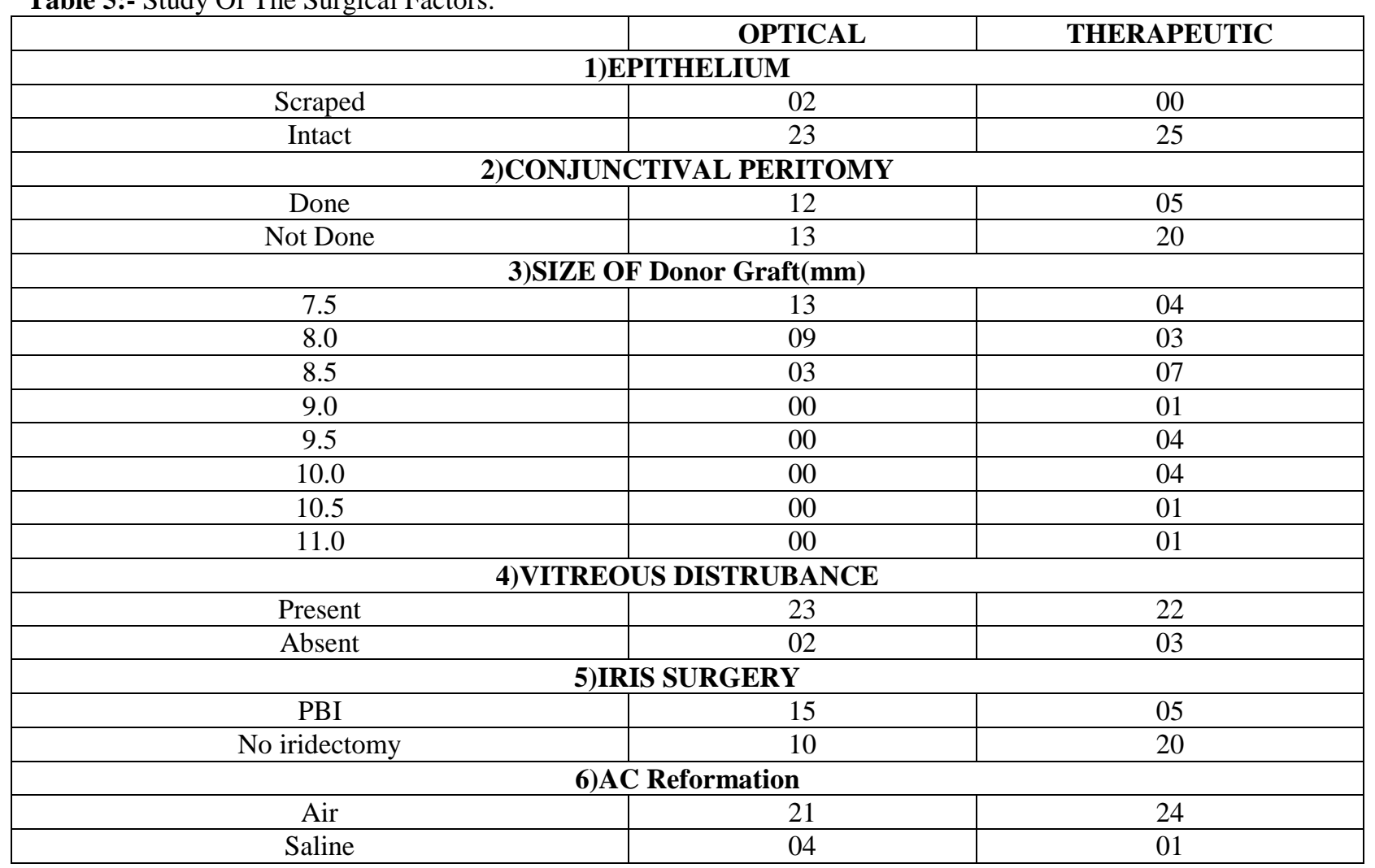

[All surgeries were performed under the operating Microscope]

The donor epithelium was left intact in majority of the cases. [92\% - Optical and 100\% - Therapeutic]

Conjunctival peritomy was done in $48 \%$ of the Optical and $20 \%$ of therapeutic cases. 
In $88 \%$ of the Optical Cases the graft size was $7.5 \mathrm{~mm}$ or $8.0 \mathrm{~mm}$ (Theoretically the best size graft). $72 \%$ of the therapeutic grafts were larger than $8.0 \mathrm{~mm}$ in an attempt to cover the host pathology in Therapeutic cases. In all cases the recipient bed prepared was $0.5 \mathrm{~mm}$ smaller than the donor graft.

Vitreous disturbance during surgery were found in total $08 \%$ cases of penetrating keratoplasty.

Peripheral button hole Iridectomy was done in $60 \%$ cases of OKP while in $20 \%$ cases of TKP all the cases.

AC Reformation is done by Air in $90 \%$ cases.

Postop. Complication:-

Table 6:- Study Of Postop. Complications.

\begin{tabular}{|l|l|l|l|l|}
\hline & OPTICAL & $\mathbf{\%}$ & THERAPEUTIC & $\mathbf{\%}$ \\
\hline Infection & 05 & 20 & 05 & 20 \\
\hline Wound Problems & 00 & 0 & 00 & 0 \\
\hline Epithelial Defect & 03 & 12 & 05 & 20 \\
\hline Uveitis & 04 & 16 & 03 & 12 \\
\hline Glaucoma & 06 & 24 & 07 & 28 \\
\hline Retrocorneal Membrane & 01 & 4 & 02 & 8 \\
\hline Cataract Formation & 01 & 4 & 07 & 28 \\
\hline Vascularization & 10 & 40 & 12 & 48 \\
\hline Rejection /Failure & 09 & 36 & 08 & 32 \\
\hline
\end{tabular}

The most common post-operative complications noticed were Vascularization [44\%] Immune rejection [34\%] glaucoma [26\% ]Uveitis [14\%] and infection [20\%].

The relative incidence of vascularization and glaucoma was higher in the Therapeutic group.

The incidence of immune rejection on the other hand was marginally higher in the Optical cases [36\%] than in the Therapeutic cases [32\%].

The incidence of Persistent Epithelial defect was 16\% [12\% in Optical and $20 \%$ in therapeutic cases.

The incidence of cataract formation was $4 \%$ in Optical cases and $28 \%$ in Therapeutic cases.

The incidence of retro corneal membrane was $4 \%$ in optical cases and $8 \%$ in therapeutic cases. [Overall incidence $6 \%]$

Probable Cause Of Graft Failure.

Table 7:- Probable Cause Of Graft Failure.

\begin{tabular}{|l|l|l|}
\hline & OPTICAL & THERAPEUTIC \\
\hline Rejection & 09 & 08 \\
\hline Primary Endothelial Failure & 04 & 06 \\
\hline Complications after Surgery & 12 & 11 \\
\hline
\end{tabular}

The most probable causes of failure in Optical and Therapeutic cases were:

1. Complications after surgery [48 \% in Optical and $44 \%$ in therapeutic cases]

2. Immune rejection reaction [36 \% in optical and $32 \%$ in therapeutic]

3. Primary Endothelial failure [16\% in Optical and $24 \%$ in therapeutic].

\section{Discussion:-}

Factors Influencing The Survival Of Graft:-

In our study, the incidence of unfavorable prognostic factors such as vascularization, history of previous cataract surgery and associated systemic disease like DM and HT was high. Wiggin's et-al noted that as high as $69 \%$ of the patients with such unfavorable factors had graft failure.

In our study majority of the donors were above 40 years. The average age of the donor eyeball was 65 years and the incidence of Primary endothelial failure was $20 \%$ overall; whereas in study conducted by Wiggins et al, the average age of the donor eyeballs was 41 years and the incidence of primary endothelial failure was $0 \%$.Thus, age of the donor eyeball appears to be a major factor in deciding endothelial function. 


\section{Post Operative Complications:-}

The incidence of infectious in our study was $20 \%$; same in the therapeutic [20\%] than on optical [20\%]. The severity varied from stitch infiltrate to frank corneal ulceration and infection was a direct cause or a contributory factor for failure. In contrast, Tuberville et al reported a $4.9 \%$ incidence of infective keratitis after PKP and attributed it to the use of corticosteroids, loose sutures, bandage contact lenses or antecedent herpetic keratitis. The post-operative infections can be a continuation of preoperative microbial keratitis.

The incidence of uveitis in our study was $14 \%$ [ $16 \%$ in optical and $12 \%$ in therapeutic].The strong correlation between intraocular inflammation[without any allograft rejection reaction] and graft opacification has been emphasized by Polack FM and he as thought of endothelial failure induced by uveitis as a cause of failure.

Our study showed vascularization in up to $40 \%$ in optical and up to $48 \%$ in therapeutic cases, and incidence of rejection was $36 \%$ and $32 \%$ respectively.

Paque $\mathrm{J}$ and Poirer R noted that neovascularization of the host interface or in the donor graft is associated with a significant increase in the risk of allograft rejection. Mittal et al noted such rejection in up to $50 \%$ of the grafts with severe vascularization. This was the cause of failure in $36 \%$ of optical and $32 \%$ of therapeutic cases in our study.

Alldredge O. C. et al consider younger age of the recipient as factor increasing risk of rejection. In our study $42 \%$ of patients were younger than 40 years.

Fine $\mathrm{M}$ et al reported that inflammatory conditions like Herpetic Keratouveitis or bacterial suppuration from a suture abscess may incite an allograft rejection reaction. In our study, infection and /or inflammation was presenting at least $50 \%$ of the cases.

In our study, the incidence of Glaucoma was $24 \%$ in Optical cases and $28 \%$ in therapeutic cases [overall 26\%] and it was directly or indirectly contributory to failure.Mittal reported $66.6 \%$ failure rate in patients with post keratoplasty glaucoma. In Arentsen's study, uncontrolled glaucoma was the cause of failure in $20 \%$ of the failed grafts; whereas in Wiggin's study, incidence of glaucoma was $16 \%$.

In all these cases, the pupil was not constricted preoperatively. Also all the patients were on high dose systemic and local steroids. Hughes et al have mentioned the real danger of producing posterior sub capsular cataract due to steroids and have reported the incidence of $19 \%$, similar to our study.

\section{Causes Of Failure:-}

In our study, the chief causes of failure were complications after surgery [46\%], Immune rejection reaction [34\%] and primary endothelial failure [20\%]; whereas in study conducted by Mittal et al the causes of failure were complications after surgery [71 \%] and immune rejection [ 29\%]. They did not have a single case of primary endothelial failure and noticed that age of the donor eyeball was not an important factor.

\section{Summary:-}

1. Overall survival rates of the grafts in our study is mainly related to post-operative complications, and proper selection of the donor tissue.

2. Chief causes of Graft failure in our study were:

1. COMPLICATIONS AFTER SURGERY-46\%

2. IMMUNE REJECTION REACTION-34\%

3. PRIMARY ENDOTHELIAL FAILURE-20\%

3. Common post-operative complications in our studying decreasing order of incidence were as follows:

1. VASCULARISATION: $44 \%$

2. IMMUNE REJECTION:34\%

3. GLAUCOMA: $26 \%$

4. INFECTION: $20 \%$

5. UVEITIS: $14 \%$

4. Maximum number of patients belonged to the age $>60$ years [38\%] with male preponderance [2.1:1 ratio] and $76 \%$ of them belonged to the lower socioeconomic status. As such, the sense of maintaining proper hygiene and awareness regarding importance of regular follow up and medication in these patients was less which can be an important factor as far as successful graft survival is concerned. 
5. Rejection rates are higher in cases where the host bed is vascularized and Conjunctival peritomy could be very much helpful in reducing the incidence of rejection rate in these cases prior to Keratoplasty.

6. Older the age of the donor eyeball, greater is the chances of Primary Endothelial Failure [ $20 \%$ in our study with the average age of the donor eyeball being 65 years].

\section{References:-}

1. Dr Noopur Gupta, Dr Radhika Tendon. Burden of Corneal blindness in India .INDIAN JOURNAL OF COMMUNITY MEDICINE, 2013 Oct-Dec; 38(4):198-206.

2. Dr Aparna c Varghese .Outcomes of a Large Series of Penetrating Keratoplasty in a Tertiary Eye Care Centre A 6 year Retrospective Study. Department .of Ophthmology, Little Flower Hospital ANGAMALAY, 2009 Dec; 23,387-395.

3. Dr Lloyd Paul Aiello. National Outcomes of Penetrating Keratoplasty. JAMA OPHTHALMOLOGY, 1993 April; 111(4)509-513

4. I Rahman, F Carley. Penetrating Keratoplasty: indication, outcomes, and complications. Department of ophthalmology, Manchester Royal Eye Hospital UK (2009) Feb; 23, 1288-1294

5. Killingworth DW. Results of Therapeutic penetrating keratoplasty .Department of ophthalmology, Univ.Florida coll. Medicine, 1993; Vol.100, 534-541

2. Hughes WF. Complications after Corneal Transplantation. American journal of ophthalmology 1966; 61:1171

3. Bright bill FS. Corneal surgery; theory technique and tissue; 1986.

4. T.A. Casey, D.J.Mayer. Corneal grafting; principal and practice; 1984.

5. A K Khurana. Comprehensive OPHTHALMOLOGY. Fourth Edition 2010; 4(5)124-126

6. Kounteya Sinha. India has largest blind population ...The Times OF India; 2007: Oct 11,

7. Corneal astigmatism after Penetrating Keratoplasty. The role of suture technique: DC Musch et al: Opthalmology, Vol 95. 15041508. AAO

8. Combined interrupted and continuous versus single continuous adjustable suturing in penetrating keratoplasty; a prospective, randomized study of induced astigmatism during the first postoperative year. CH Karabatsas et al: Ophthalmology, Vol 101,113-119,AAO 1994.

9. Cataract Formation and Cataract Extraction after Penetrating Keratoplasty: TP Martin et al: Ophthalmology, Vol 97, 934- 938, AAO [1990]

10. Corneal Epithelium following Penetrating Keratpolasty: K Tsubota, Y Mashima et al: British Journal of Ophthalmology, 192, Vol 76, 98-100.

11. Corneal Grafting: Principles and Practice, T.A Casey, D.J.Mayer, Philadelphia, 1984, WBSaunders \& Co.

12. Corneal Surgery: Theory, Technique and Tissue: edited by Brightbill FS. 1986, CV Mosby and Company 